\title{
Anthocyanin and Phenolic Acid Profiles in Purple, Red and Non-Pigmented Rice during Germination
}

\author{
Supapohn Yamuangmorn ${ }^{1}$, Bernard Dell ${ }^{2}$, and Chanakan Prom-u-thai ${ }^{1,3^{*}}$ \\ ${ }^{1}$ Agronomy Division, Department of Plant and Soil Sciences, Faculty of \\ Agriculture, Chiang Mai University, Chiang Mai 50200, Thailand \\ ${ }^{2}$ Agricultural Sciences, Murdoch University, Murdoch, WA, 6150, Australia \\ ${ }^{3}$ Lanna Rice Research Center, Chiang Mai University, Chiang Mai 50200, \\ Thailand
}

*Corresponding author.Email: chanakan.p@cmu.ac.th,chanakan15@hotmail.com https://doi.org/10.12982/CMUJNS.2020.0054

Received: November 19, 2019

Revised: February 19, 2020

Accepted: March 11, 2020

\begin{abstract}
There is a growing interest in using germinated rice in health products based on their antioxidant properties but studies exploring differences in pigmented and non-pigmented rice types are limited. Therefore, anthocyanin and phenolic acid contents and composition were quantified using UPLC over 6 days of germination in three pigmented (two purple and one red) and one non-pigmented rice genotypes. Most of the anthocyanin content in purple rice, mainly cyanidin-3-glucoside and peonidin-3-glucoside, was lost during the imbibition and radicle emergence phase of germination. By contrast, there were only small changes in free and bound phenolic acid fractions over the 6 days of germination in all genotypes. Vanillic and ferulic acids comprised the main components of the free and bound pools, respectively. Vanillic acid contents, but not ferulic acid, were considerably greater in purple rice than in red and non-pigmented rice. Germination rapidly decreased the anthocyanin content in purple rice, but only had a minor effect on the free and bound phenolic acids in purple, red and non-pigmented rice. The increasing content of bound p-coumaric, ferulic and vanillic acids in germinated purple rice may provide an opportunity to develop rice products as functional foods.
\end{abstract}

Keywords: Pigmented rice, Purple rice, Germination, Anthocyanin, Phenolic acid 


\section{INTRODUCTION}

Rice has one of the most diverse grain colors of all the cereals with red, black, purple and brown pericarps which the latter is known as non-colored rice. Although polished brown rice is the most widely consumed type in the world, colored or pigmented rice is increasingly becoming an important part of a healthy diet. Pigmented grains, such as blue wheat, blue maize and purple rice, are often promoted as health foods because they contain high amounts of antioxidants, especially anthocyanins (Ghasemzadeh et al., 2018; Sivamaruthi et al., 2018; Chavarín-Martínez et al., 2019). Anthocyanin is one of the colored antioxidants located in the pericarp layers of the seed resulting in colored grain (Zhang et al., 2010). Besides anthocyanin, rice contains free and bound phenolic acids (Goufo and Trindade, 2014). Rice anthocyanins and phenolic acids are gaining interest as potential and natural nutritional supplements for reducing the level of oxidation damage in humans (Shimoda et al., 2015; Russo et al., 2017).

A number of techniques are being used to improve the nutrient value of rice products, and these include roasting, parboiling and germination. Germination may improve the nutritional quality of grain through enhancement of proteins, essential amino acids and vitamins (Sibian et al., 2017). Although increases in bioactive compounds in germinated edible seeds and sprouts have received some attention (Gan et al., 2017), the optimum conditions have not been defined in all cereals. Germination stage has been evaluated in order to enhance antioxidant capacity and phenolic acid content in non-pigmented rice ( $\mathrm{Ti}$ et al., 2014), but not in pigmented rice. Recently, germinated unpolished brown rice has been developed as the main ingredient in a fermentation process giving a yogurtlike product and bread (Cornejo et al., 2015; Cáceres et al, 2019). However, the change in anthocyanin, anthocyanidin and phenolic acid profiles in different Thai rice grain pericarps during germination is not documented. Therefore, the aim of this study was to characterize dynamic changes in the anthocyanin and phenolic acid profiles of pigmented and non-pigmented rice varieties during germination.

\section{MATERIALS AND METHODS}

\section{Rice material}

Four photo-period sensitive rice genotypes were used in this study: two traditional improved purple rice genotypes, Kum Doi Saket (KDK) and CMU 125; and two popular commercial Thai genotypes, Red Hawm Rice (RHR) and Khao Dawk Mali 105 (KDML 105) with red and non-pigmented pericarps, respectively. Seeds of RHR and KDML 105 were obtained from a commercial supplier (All Rice Surin Shop, Surin province, Thailand) from the current year's harvest, and seed of KDK and CMU 125 were from experimental crops grown in a field in the wet season (August - December) of 2016 on a Sansai series soil at 
Chiang Mai University, Chiang Mai, Thailand ( $\left.18^{\circ} 47^{\prime} \mathrm{N}, 98^{\circ} 57^{\prime} \mathrm{E}\right)$. Procedures for growing the Chiang Mai crops have been described previously (Yamuangmorn et al., 2019). The grain of all genotypes was harvested by manual threshing and then air-dried until the moisture content fell to approximately $14 \%$. The rough (i.e. unhusked or paddy) rice was kept in zip-lock plastic bags and stored in a cool room at $16^{\circ} \mathrm{C}$ in the dark until used.

\section{Preparation of germinated rice flour}

About $100 \mathrm{~g}$ of rough rice was surface sterilized in $70 \%$ ethanol and washed twice with distilled water. Sterilized samples were soaked for $24 \mathrm{~h}$ in distilled water with a ratio of $1: 2(\mathrm{w} / \mathrm{v})$ at room temperature $\left(25^{\circ} \mathrm{C}\right)$. The samples were then rinsed again before being subjected to germination in three separate experiments. The rough rice was evenly distributed on wet filter paper before being placed in closed plastic baskets in a controlled growth chamber at $30^{\circ} \mathrm{C}$. The humidity was controlled by adding water equally every day. Germinated grain sub-samples were taken 2 days (D2, radicle emerged), 4 days (D4, leaf just emerged from coleoptile) and 6 days (leaf approximately $2 \mathrm{~cm}$ in length) after commencement of soaking. The sub-samples were dried at $75^{\circ} \mathrm{C}$ for $24 \mathrm{~h}$ to halt metabolism. The husk, root and shoot were removed manually by hand as the objective was to determine changes in the seed, not seedling tissues during germination. Approximately $20 \mathrm{~g}$ grain sub-samples were mechanically ground for $60 \mathrm{~s}$ in a hammer mill (Scientific Technical Supplies D-6072 Dreieich, West Germany) to prepare rice flour. Non-germinated husked rice was used as control samples (D0). Flour samples were kept in zip lock plastic bags and stored in a freezer at $-25^{\circ} \mathrm{C}$ until analysis. Three biological replicates were used for each analytical procedure.

\section{Extraction and determination of anthocyanins and phenolic acids by UPLC}

Anthocyanins and phenolic acids were extracted based on a published method (Yamuangmorn et al., 2019). Briefly, flour samples (0.5 g) were extracted with acidified $\mathrm{MeOH}(15 \mathrm{~mL}$ of $1.0 \mathrm{~N} \mathrm{HCl}$ in $85 \mathrm{~mL}$ of $\mathrm{MeOH})$ on a mechanical shaker for $1 \mathrm{~h}$. The extract solution was centrifuged at $4,000 \times \mathrm{g}$ for $10 \mathrm{~min}$ at room temperature and then filtered through $0.22 \mu \mathrm{m}$ Nylon membrane before analysis. After removal of anthocyanin and free phenolic acids, the bound phenolic acids were extracted using a hydrolysis protocol according to the above developed methods.

UPLC analysis was performed on a Waters Acquity UPLC equipped with a photodiode-array detector (PDA) and a Zorbax Eclipse C18 column $(2.1 \times 100$ $\mathrm{mm}, 3.5 \mu \mathrm{m}$ particle size) to separate the compounds. The gradient elution mobile phases were $0.1 \%$ (vol/vol) formic acid in water (mobile phase A) and $0.1 \%(\mathrm{v} / \mathrm{v})$ formic acid in methanol (mobile phase B). The UPLC condition, reference compounds (cyanindin-3-glucoside, peonidin-3-glucoside, cyanidin, peonidin, 
p-coumaric acid, ferulic acid and vanillic acid) and reagents followed by a published method (Yamuangmorn et al., 2019). Separation conditions were assayed using standard solutions at concentrations within 0-30 $\mu \mathrm{g} / \mathrm{mL}$. The absorbance was measured at $500 \mathrm{~nm}, 310 \mathrm{~nm}, 320 \mathrm{~nm}$ and $260 \mathrm{~nm}$ for anthocyanin compounds, $p$-coumaric acid, ferulic acid and vanillic acid respectively.

\section{Statistical analysis}

Differences in mean parameters (concentrations of total and individual anthocyanins, total and individual phenolic acids) of three biological replicates for germination time and rice genotype were determined by a two-way analysis of ANOVA using Statistix version 9.0 statistical software followed by the post hoc LSD test at $95 \%$ confidence level $(P<0.05)$.

\section{RESULTS}

\section{Anthocyanins and phenolic acids content in non-germinated rice}

The total anthocyanin content, determined by the sum of individual anthocyanins, differed between the two purple rice genotypes $(P<0.05)$ (Figure 1A). CMU 125 had about 1.7 times higher total anthocyanin content than KDK. No anthocyanins were detected in red RHR and the non-pigmented rice KDML 105 flours. The total phenolic acid content, determined by the sum of individual free and bound phenolic acid fractions, also differed among the four genotypes $(P<0.05)$ (Figure 1B). KDK had 0.2 times higher total phenolic acid content than CMU 125, while the RHR and KDML 105 genotypes had 0.2-0.6 times lower total phenolic acid content than KDK and CMU 125.
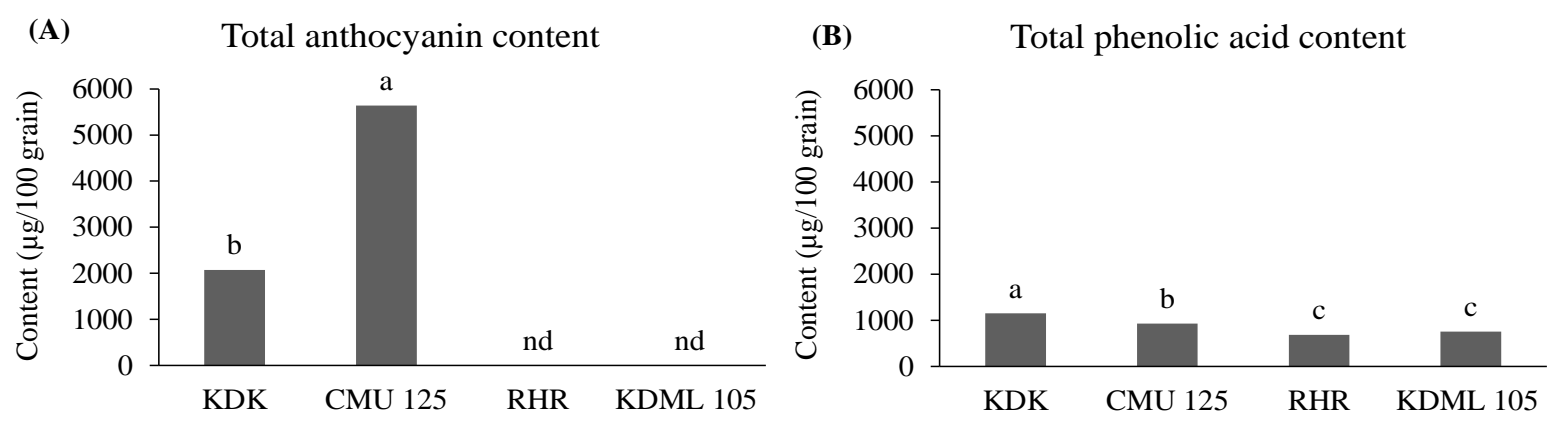

Figure 1. Content of total anthocyanin (A) and total phenolic acid (B) in nongerminated rice of four genotypes. 


\section{Individual anthocyanins content in germinated rice}

The UPLC analysis showed that the contents of cyanidin-3-glucoside and peonidin-3-glucoside of the two purple genotypes, KDK and CMU 125, decreased rapidly with germination $(P<0.05)$ (Table 1$)$. The cyanidin-3-glucoside content declined from 1,489.0 to 80.2 and from 4,939.1 to $316.5 \mu \mathrm{g} / 100$ grain in KDK and CMU 125, respectively. Most of the loss occurred during imbibition and early growth of the radicle, as by D2 the average cyanidin-3-glucoside content in both genotypes had fallen by approximately $74 \%$. Only a small decrease in the cyanidin-3-glucoside content occurred from D4 to D6. The peonidin-3-glucoside content followed a similar trajectory to cyanidin-3glucoside, declining from 570.5 to 20.1 and from 675.4 to $36.6 \mu \mathrm{g} / 100$ grain in KDK and CMU 125, respectively, being a decrease of about $75 \%$ at D2. The cyanidin and peonidin contents of the two purple genotypes also decreased rapidly with germination $(P<0.05)$ (Table 1$)$. Over the period D0 to D6, the cyanidin contents of KDK and CMU 125 declined from 3.7 to 0.4 and 22.8 to 3.2 $\mu \mathrm{g} / 100$ grain, respectively. On a percentage basis, the cyanidin contents of KDK and CMU 125 fell by 46 and $56 \%$ by D2, respectively. Similarly, the peonidin contents of KDK and CMU 125 declined from 0.8 to 0.0 and 3.6 to $0.2 \mu \mathrm{g} / 100$ grains, respectively, during germination. Half of the peonidin content was lost during the first two days.

The decline in total anthocyanin content with germination, determined by the sum of individual anthocyanins differed among the two purple genotypes $(P<0.05)$ (Table 1), declining from 2,073 to 101 and 5,641 to $356 \mu \mathrm{g} / 100$ grain in KDK and CMU 125, respectively. Most of the loss occurred early (D2), 75\% in $\mathrm{KDK}$ and $73 \%$ in CMU 125.

Table 1. Changes in the content $(\mu \mathrm{g} / 100$ grain rice flour) of cyanidin-3glucoside, peonidin-3-glucoside, cyanidin, peonidin and total anthocyanins in two purple rice genotypes during germination.

\begin{tabular}{lcrrrrrrrrrr}
\hline Genotype & Day & $\begin{array}{l}\text { Cyanidin-3- } \\
\text { glucoside }\end{array}$ & $\begin{array}{l}\text { Peonidin-3- } \\
\text { glucoside }\end{array}$ & Cyanidin & Peonidin & \multicolumn{2}{l}{ Total } \\
anthocyanins
\end{tabular}

Note: Values with different lowercase letters in the same column are significantly different $(P<0.05)$ among various germination stages in each individual genotype. Values with different uppercase letters are significantly different $(P<0.05)$ among genotype and time of germination. 
Individual free phenolic acid and total free phenolic acids in germinated rice

Germination affected the free $p$-coumaric acid contents in all rice genotypes, except in KDK $(P<0.05)$ (Table 2$)$. The free $p$-coumaric acid of CMU 125 remained unchanged from D0 to D4, then declined by $56 \%$. By contrast, the free $p$-coumaric acid contents of RHR and KDML 105 increased during germination, by 200 and 353\%, respectively, at D6 compared with the content before germination. Germination altered $(P<0.05)$ the free ferulic acid content of KDK and CMU 125 (Table 2). The content of this acid in KDK decreased by approximately $51 \%$ at D2 and D4, but then recovered by D6. However, in CMU 125 there was no recovery after the initial reduction of $29 \%$. In addition, the free vanillic acid content was affected by germination in KDK and KDML 105, but not in CMU 125 and RHR $(P<0.05)$ (Table 2$)$. In KDK, the content decreased at D4 and then increased to exceed that in non-germinated seeds by $19 \%$ at D6. Similarly, the content of KDML 105 declined by approximately $35 \%$ at D2 and D4 and increased by $82 \%$ at D6.

Table 2. Changes in content ( $\mu \mathrm{g} / 100$ grain rice flour) of free individual phenolic acids and total free phenolic acid of four rice genotypes at different germination stages.

\begin{tabular}{|c|c|c|c|c|c|c|c|c|c|}
\hline \multirow{2}{*}{$\begin{array}{l}\text { Genotype } \\
\text { KDK }\end{array}$} & \multirow{2}{*}{$\begin{array}{l}\text { Day } \\
0\end{array}$} & \multicolumn{2}{|c|}{$\begin{array}{l}p \text {-coumaric } \\
\text { acid }\end{array}$} & \multicolumn{2}{|c|}{ Ferulic acid } & \multicolumn{2}{|c|}{ Vanillic acid } & \multicolumn{2}{|c|}{$\begin{array}{l}\text { Total free } \\
\text { phenolic acids }\end{array}$} \\
\hline & & 5.0 & $\mathrm{a}$ & 6.5 & $a b$ & 38.2 & $\mathrm{~b}$ & 49.7 & $\mathrm{~A}$ \\
\hline & 2 & 3.4 & $\mathrm{a}$ & 3.0 & $\mathrm{~b}$ & 36.4 & $\mathrm{bc}$ & 42.8 & B \\
\hline & 4 & 3.2 & $\mathrm{a}$ & 3.4 & $\mathrm{~b}$ & 32.7 & $\mathrm{c}$ & 39.3 & B \\
\hline & 6 & 4.7 & $\mathrm{a}$ & 7.0 & $\mathrm{a}$ & 42.9 & $\mathrm{a}$ & 56.6 & A \\
\hline \multirow[t]{4}{*}{ CMU 125} & 0 & 8.7 & $\mathrm{a}$ & 6.6 & $\mathrm{a}$ & 24.3 & $\mathrm{a}$ & 41.0 & $\mathrm{~B}$ \\
\hline & 2 & 6.6 & $a b$ & 5.9 & $a b$ & 26.3 & $\mathrm{a}$ & 40.1 & $\mathrm{BC}$ \\
\hline & 4 & 5.8 & b & 4.8 & $\mathrm{~b}$ & 22.5 & $\mathrm{a}$ & 34.4 & $\mathrm{C}$ \\
\hline & 6 & 3.8 & $\mathrm{~b}$ & 4.6 & $\mathrm{~b}$ & 25.1 & $\mathrm{a}$ & 33.5 & $\mathrm{C}$ \\
\hline \multirow[t]{4}{*}{ RHR } & 0 & 1.0 & c & 2.7 & $\mathrm{a}$ & 2.0 & $\mathrm{a}$ & 5.6 & $\mathrm{E}$ \\
\hline & 2 & 2.8 & $a b$ & 3.4 & $\mathrm{a}$ & 2.9 & $\mathrm{a}$ & 9.1 & $\mathrm{E}$ \\
\hline & 4 & 2.1 & $\mathrm{~b}$ & 3.2 & $\mathrm{a}$ & 1.5 & $\mathrm{a}$ & 6.7 & $\mathrm{E}$ \\
\hline & 6 & 3.0 & $\mathrm{a}$ & 3.1 & $\mathrm{a}$ & 3.4 & $\mathrm{a}$ & 9.5 & $\mathrm{E}$ \\
\hline \multirow[t]{4}{*}{ KDML 105} & 0 & 1.7 & $\mathrm{c}$ & 3.4 & $\mathrm{~b}$ & 1.7 & $\mathrm{~b}$ & 6.7 & $\mathrm{E}$ \\
\hline & 2 & 2.6 & $\mathrm{bc}$ & 3.7 & $\mathrm{~b}$ & 1.2 & $\mathrm{c}$ & 7.5 & $\mathrm{E}$ \\
\hline & 4 & 3.6 & b & 5.0 & $a b$ & 1.0 & $\mathrm{c}$ & 9.6 & $\mathrm{E}$ \\
\hline & 6 & 7.7 & $\mathrm{a}$ & 5.6 & $\mathrm{a}$ & 3.1 & $\mathrm{a}$ & 16.4 & D \\
\hline
\end{tabular}

Note: Values with different lowercase letters in the same column are significantly different $(P<0.05)$ among various germination stages in each individual genotype. Values with different uppercase letters are significantly different $(P<0.05)$ among genotype and germination stage.

The response in total free phenolic acid content with germination, determined by the sum of individual phenolic acids differed among the four genotypes $(P<0.05)$ (Table 2$)$. The total free phenolic acid content of KDK 
declined by approximately $17 \%$ (D2 to D4), then recovered. A similar decline occurred in CMU 125, but there was no recovery. For KDML 105, the total free phenolic acid contents at D2 and D4 were the same as in non-germinated seed, but by D6 the content had increased by $146 \%$. In RHR, however, the content of the free phenolic acids did not change with germination.

\section{Individual bound phenolic acid and total bound phenolic acids in germinated rice}

The bound $p$-coumaric acid contents in all rice genotypes increased $(P<0.05)$ (Table 3) during germination, reaching maxima at D5 with increases of 253, 262, 36 and 35\% for KDK, CMU 125, RHR and KDML 105, respectively. Germination also affected $(P<0.05)$ the bound ferulic acid contents of KDK, CMU 125 and KDML 105, but not RHR (Table 3). The bound ferulic acid contents of KDK and CMU 125 increased by $26 \%$ in KDK and $17 \%$ in CMU 125 after D2. A similar increase of $43 \%$ was observed in KDML 105 at D4, but then it declined by $36 \%$ at D6 as compared to D4. Furthermore, germination increased $(P<0.05)$ the bound vanillic acid contents of KDK and CMU 125 by about 58 and $42 \%$, respectively, at D6, but there was no change in RHR and KDML 105 (Table 3).

Table 3. Changes in content $(\mu \mathrm{g} / 100$ grain rice flour) of bound phenolic acids and total bound phenolic acid of four rice genotypes at different germination stages.

\begin{tabular}{|c|c|c|c|c|c|c|c|c|c|}
\hline \multirow{2}{*}{$\begin{array}{l}\text { Genotype } \\
\text { KDK }\end{array}$} & \multirow{2}{*}{$\begin{array}{l}\text { Day } \\
0\end{array}$} & \multicolumn{2}{|c|}{$\begin{array}{l}p \text {-coumaric } \\
\text { acid }\end{array}$} & \multicolumn{2}{|c|}{ Ferulic acid } & \multicolumn{2}{|c|}{ Vanillic acid } & \multicolumn{2}{|c|}{$\begin{array}{l}\text { Total bound } \\
\text { phenolic acids }\end{array}$} \\
\hline & & 46.7 & $\mathrm{c}$ & 895.4 & $\mathrm{~b}$ & 161.5 & $\mathrm{~b}$ & $1,103.6$ & $\mathrm{BC}$ \\
\hline & 2 & 51.0 & $\mathrm{c}$ & 947.4 & $\mathrm{~b}$ & 190.0 & $\mathrm{~b}$ & $1,188.3$ & B \\
\hline & 4 & 134.4 & $b$ & $1,180.9$ & $\mathrm{a}$ & 230.8 & $\mathrm{a}$ & $1,546.1$ & A \\
\hline & 6 & 164.9 & a & $1,077.6$ & $\mathrm{a}$ & 255.2 & $\mathrm{a}$ & $1,497.7$ & A \\
\hline \multirow[t]{4}{*}{ CMU 125} & 0 & 32.3 & $\mathrm{c}$ & 773.6 & $\mathrm{~b}$ & 84.4 & $\mathrm{~b}$ & 890.3 & $\mathrm{D}$ \\
\hline & 2 & 55.1 & $\mathrm{~b}$ & 729.3 & $\mathrm{~b}$ & 86.1 & $\mathrm{~b}$ & 870.4 & $\mathrm{DE}$ \\
\hline & 4 & 113.2 & $\mathrm{a}$ & 905.9 & $\mathrm{a}$ & 108.0 & $\mathrm{a}$ & $1,127.1$ & $\mathrm{BC}$ \\
\hline & 6 & 117.0 & $\mathrm{a}$ & 829.9 & $a b$ & 120.6 & $\mathrm{a}$ & $1,067.5$ & $\mathrm{C}$ \\
\hline \multirow[t]{4}{*}{ RHR } & 0 & 134.8 & $\mathrm{~b}$ & 541.8 & $a b$ & 3.2 & $\mathrm{a}$ & 679.8 & $\mathrm{~F}$ \\
\hline & 2 & 138.3 & $\mathrm{~b}$ & 583.4 & $\mathrm{a}$ & 5.8 & $\mathrm{a}$ & 727.6 & $\mathrm{~F}$ \\
\hline & 4 & 167.9 & $\mathrm{a}$ & 592.8 & $\mathrm{a}$ & 5.8 & $\mathrm{a}$ & 766.5 & $\mathrm{EF}$ \\
\hline & 6 & 183.7 & $\mathrm{a}$ & 500.3 & $a b$ & 5.6 & $\mathrm{a}$ & 689.7 & $\mathrm{~F}$ \\
\hline \multirow[t]{4}{*}{ KDML 105} & 0 & 130.4 & $\mathrm{c}$ & 612.4 & $\mathrm{~b}$ & 5.5 & $\mathrm{a}$ & 748.3 & $\mathrm{~F}$ \\
\hline & 2 & 146.8 & $\mathrm{~b}$ & 633.1 & $\mathrm{~b}$ & 3.1 & $\mathrm{a}$ & 783.1 & DEF \\
\hline & 4 & 158.0 & $a b$ & 876.6 & $\mathrm{a}$ & 3.5 & $\mathrm{a}$ & $1,038.0$ & $\mathrm{C}$ \\
\hline & 6 & 162.6 & $\mathrm{a}$ & 558.3 & $\mathrm{~b}$ & 3.4 & $\mathrm{a}$ & 724.3 & $\mathrm{~F}$ \\
\hline
\end{tabular}

Note: Values with different lowercase letters in the same column are significantly different $(P<0.05)$ among various germination stages in individual genotype. Values with different uppercase letters are significantly different $(P<0.05)$ among genotype and germination stage. 
The change in total bound phenolic acid content with germination, determined by the sum of individual phenolic acids differed among the four genotypes $(P<0.05)$ (Table 3$)$. The total bound phenolic acid contents of KDK and CMU 125 increased (D4 to D6) by up to 39 and 23\%, respectively, compared with contents before germination. By contrast, the content of KDML 105 first increased (39\% at D4) then fell by 30\% (D4 to D6). The total bound phenolic acid content of RHR remained unchanged during germination.

\section{DISCUSSION}

Seed germination may alter the antioxidant capacity of rice due to changes in chemical composition, structure and synthesis of new components, or transformation of primary or secondary metabolites (Lin et al., 2015; Jirapa et al., 2016). The mechanism of anthocyanin degradation cause by increasing of $\mathrm{pH}$ and thermal condition has been extremely studied, whereas knowledge regarding its degradation by germination process is limited (Patras et al., 2010). The observed decrease in anthocyanin content of more than half of the initial content over the first two days of germination is in accordance with observations that anthocyanin leached into water when purple rice was soaked (Noorlaila et al., 2018). Even, this study was not detected anthocyanin loss in soaked water due to the type of paddy rice used, anthocyanins are water-soluble compounds located mainly in the rice pericarp, and it is likely that the structural breakdown of cell walls begins to liberate anthocyanins during imbibition and cell growth. On the other hand, the transformation of the pyrylium ring of anthocyanins, leading to cleavage of the glycoside linkage and formation of the chalcone structure (colorless form) may lead to the initial reduction step of anthocyanins during germination (Patras et al., 2010). Comparing the anthocyanin contents between soaked grain and soaked water would be useful to confirm the water-soluble of anthocyanin. Similarly, the cyanidin-3-glucoside pool in purple corn decreased by $34 \%$ after germination for $63 \mathrm{~h}$, while peonidin-3-glucoside declined only by 5\% (Paucar-Menacho et al., 2017). These results are contrasted to a recent study by Owolabi et al. (2019) found that the total anthocyanin content to increase in purple rice after soaking and germination process. However, soaking for $24 \mathrm{~h}$ followed by $12 \mathrm{~h}$ of germination did not reduce the total anthocyanin content of two purple rice determined with a spectrophotometer (Thao and Niwat, 2017). On the other hand, the total anthocyanin content in black rice showed a decline at earlier stages but it recovered at the later stages during germination (Wang et al., 2016). Such discrepancies between studies might be due to the use of different analytical methods, germination conditions or rice genotypes differing in the amount of natural anthocyanin content in the pericarp. This study indicated that the breakdown of cyanidin-3-glucoside or peonidin-3-glucoside did not result in an increase in the cyanidin or peonidin content, as presumably all were degraded. 
It is possible that anthocyanin and anthocyanidin might have been transformed into protocatechuic acid and/or 4-hydroxlybenzoic acid (Nayak et al., 2015) during germination but these were not assayed. Our UPLC method was not optimized for the measurement of proanthocyanidins so we were unable to quantify changes in the main pigment in red rice on germination. Other studies have reported on proanthocyanidins in red rice (Upanan et al., 2019), but not during germination.

Unlike anthocyanin in purple rice, there were only small changes in free and bound phenolic acid fractions over the 6 days of germination in all varieties. Any change in phenolic acid content and composition during germination reflects the balance between liberation, degradation and synthesis. The slight decrease in free phenolic acid content in purple rice early in germination likely reflects some leaching during imbibition. Much of the phenolic acids were present in the waterinsoluble pool which is likely to be more stable during the presence of free water. With the progress of germination, the bound phenolic acid fraction increased, in conjunction with new cell wall matrix formed during growth of seedling tissues (Shahidi and Yeo, 2016). The activity of cell wall peroxidases, the enzyme which liberates phenolic acid, is induced by germination (Wakabayashi et al., 2015). Also, an increase in bound phenolic acid in non-pigmented rice was shown to be positively correlated with cell wall peroxidase activity after 4 days of germination (Cho and Lim, 2018). Furthermore, some phenolic acids, including vanillic acid, may be products of the degradation of cyanidin and peonidin during fermentation (Zhu et al., 2018). Besides the liberation and degradation of anthocyanin, the increase in phenolic acid could be due to the synthesis of phenolic compounds from the induction of hydrolytic enzymes. In a study on germinated nonpigmented rice, the germination process increased the activity of phenylalanine ammonia-lyase, isoflavone-7-methyltransferase, glutathione S-transferase and UDP-glucose flavonoid-3-glucosyltransferase (Maksup et al., 2018). In germinated wheat, high expression levels of phenylalanine ammonia-lyase and some other proteins were positively related to the accumulation of phenolic acids and germination time (Chen et al., 2017; Kim et al., 2018).

The presence of vanillic acid in both free and bound fractions could be only quantified in purple rice, as the levels in red and non-pigmented rice were very low. The contents of vanillic acid in Thai rice were similar to Chinese rice, showing that purple rice contains both free and bound fractions of vanillic acid, but the free fraction was not detected in red and non-pigmented rice (Shao et al., 2018), suggesting that vanillic acid was considerably greater in purple rice than in varieties lacking anthocyanins. Thus, it could be expected that the distribution of individual phenolic acid in free and bound fractions among different rice grains might be associated with the distribution patterns of phenolic compounds in different tissue fractions. It has been reported that the contents of free and bound ferulic acid can vary with tissue types with most of the free fraction accumulating 
in the embryo and most of the bound fraction being located in the bran (Ti et al., 2015).

There is an interesting point as to the increasing interested phenolic acids and the remained anthocyanins in purple rice, especially in CMU125 genotype for functional foods and products such as concentrated capsules and sprouted powder due to their potential benefit for human health. Thus, the increasing content of bound $p$-coumaric, ferulic and vanillic acids in germinated purple rice may provide an opportunity to develop germinated rice products as healthy foods. However, more research is required to establish the unequivocal benefit of rice phenolics for human health. In addition, other key antioxidants, such as proanthocyanidin in red rice, should be evaluated as a source of antioxidants in germinated red rice food products. The results from this study should be of interest to traders and food industries wishing to use germinated purple rice in product development.

\section{CONCLUSION}

Cyanidin-3-glucoside and peonidin-3-glucoside in purple rice fell markedly during the early stages of germination. By contrast, there were only small changes in free and bound phenolic acid fractions over the 6 days of germination in all genotypes. The increase in bound $p$-coumaric, ferulic and vanillic acids in germinated purple and non-pigmented rice at D4 suggests that sprouted rice could be considered for the development of rice products. Further research on differences between rice genotypes and responses of phenolic acids to germination should be undertaken to provide a stronger basis for the emerging commerce in rice products for human health.

\section{ACKNOWLEDGMENTS}

We are grateful to the Thailand Research Fund (RSA6080024) and Chiang Mai University, Thailand for financial support.

\section{REFERENCES}

Cáceres, P.J., Peñas, E., Martínez-Villaluenga, C., García-Mora, P., and Frías, J. 2019. Development of a multifunctional yogurt-like product from germinated brown rice. LWT- Food Science and Technology. 99: 306-312. https://doi.org/10.1016/j.lwt.2018.10.008 
Chavarin-Martinez, C.D., Gutierrez-Dorado, R., Perales-Sanchez, J.X.K., Cuevas-Rodriguez, E.O., Milan-Carrillo, J., and Reyes-Moreno, C. 2019. Germination in optimal conditions as effective strategy to improve nutritional and nutraceutical value of underutilized Mexican blue maize seeds. Plant Foods for Human Nutrition. 74(2): 192-199. https://doi.org/ 10.1007/s11130-019-00717-X

Chen, Z., Wang, P., Weng, Y., Ma, Y., Gu, Z., and Yang, R. 2017. Comparison of phenolic profiles, antioxidant capacity and relevant enzyme activity of different Chinese wheat varieties during germination. Food Bioscience. 20: 159-167. https://doi.org/10.1016/j.fbio.2017.10.004

Cornejo, F., Caceres, P.J., Martinez-Villaluenga, C., Rosell, C.M., and Frias, J. 2015. Effects of germination on the nutritive value and bioactive compounds of brown rice breads. Food Chemistry. 173: 298-304. https://doi.org/10.1016/j.foodchem.2014.10.037

Cho, D.H., and Lim, S.T. 2018. Changes in phenolic acid composition and associated enzyme activity in shoot and kernel fractions of brown rice during germination. Food Chemistry. 256: 163-170. https://doi.org/10. 1016/j.foodchem.2018.02.040

Gan, R.Y., Lui, W.Y., Wu, K., Chan, C.L., Dai, S.H., Sui, Z.Q., and Corke, H. 2017. Bioactive compounds and bioactivities of germinated edible seeds and sprouts: an updated review. Trends in Food Science \& Technology. 59: 1-14. https://doi.org/10.1016/j.tifs.2016.11.010

Ghasemzadeh, A., Karbalaii, M.T., Jaafar, H.Z.E., and Rahmat, A. 2018. Phytochemical constituents, antioxidant activity, and antiproliferative properties of black, red, and brown rice bran. Chemistry Central Journal. 12: 17. https://doi.org/10.1186/s13065-018-0382-9

Goufo, P., and Trindade, H. 2014. Rice antioxidants: phenolic acids, flavonoids, anthocyanins, proanthocyanidins, tocopherols, tocotrienols, gammaoryzanol, and phytic acid. Food Science \& Nutrition. 2(2): 75-104. https://doi.org/10.1002/fsn3.86

Jirapa, K., Jarae, Y., Phanee, R., and Jirasak, K. 2016. Changes of bioactive components in germinated paddy rice (Oryza sativa L.). International Food Research Journal. 23(1): 229-236.

Kim, M.J., Kwak, H.S., and Kim, S.S. 2018. Effects of germination on protein, gamma-aminobutyric acid, phenolic acids, and antioxidant capacity in wheat. Molecules. 23(9): 2244. https://doi.org/10.3390/molecules230922 44

Lin, Y., Xu, W., Huang, M., Xu, W., Li, H., Ye, M., Zhang, X., and Chu, K. 2015. Qualitative and quantitative analysis of phenolic acids, flavonoids and iridoid glycosides in Yinhua Kanggan tablet by UPLC-QqQ-MS/MS. Molecules. 20(7): 12209-12228. https://doi.org/10.3390/molecules200712 209 
Maksup, S., Pongpakpian, S., Roytrakul, S., Cha-Um, S., and Supaibulwatana, K. 2018. Comparative proteomics and protein profile related to phenolic compounds and antioxidant activity in germinated Oryza sativa 'KDML105' and Thai brown rice 'Mali Daeng' for better nutritional value. Journal of the Science of Food and Agriculture. 98(2): 566-573. https://doi. org/10.1002/jsfa. 8498

Nayak, B., Liu, R.H., and Tang, J. 2015. Effect of processing on phenolic antioxidants of fruits, vegetables, and grains-A review. Critical Reviews in Food Science and Nutrition. 55(7): 887-918. https://doi.org/ 10.1080/10408398.2011.654142

Noorlaila, A., Nur Suhadah, N., Noriham, A., and Nor Hassan, H. 2018. Total anthocyanin content and antioxidant activities of pigmented black rice (Oryza Sativa L. Japonica) subjected to soaking and boiling. Jurnal Teknologi (Sciences \& Engineering). 80(3): 137-143. https://doi.org/ 10.11113/jt.v80.11135

Owolabi, I.O., Chakree, K., and Yupanqu, C.T. 2019. Bioactive components, antioxidative and anti-inflammatory properties (on RAW 264.7 macrophage cells) of soaked and germinated purple rice extracts. International Journal of Food Science and Technology. 54: 2374-2386. https://doi.org/10.1111/ijfs.14148

Paucar-Menacho, L.M., Martínez-Villaluenga, C., Dueñas, M., Frias, J., and Peñas, E. 2017. Optimization of germination time and temperature to maximize the content of bioactive compounds and the antioxidant activity of purple corn (Zea mays L.) by response surface methodology. LWT Food Science and Technology. 76 (Part B): 236-244. http://doi.org/10. 1016/j.lwt.2016.07.064

Patras, A., Brunton, N.P., O'Donnell, C., and Tiwari, B.K. 2010. Effect of thermal processing on anthocyanin stability in foods; mechanisms and kinetics of degradation. Trends in Food Science \& Technology. 21(1): 3-11. https:// doi.org/10.1016/j.tifs.2009.07.004

Russo, G.I., Campisi, D., Di Mauro, M., Regis, F., Reale, G., Marranzano, M., Ragusa, R., Solinas, T., Madonia, M., Cimino, S., et al. 2017. Dietary consumption of phenolic acids and prostate cancer: a case-control study in sicily, Southern Italy. Molecules. 22(12): e2159. https://doi.org/10.3390/ molecules22122159

Shahidi, F., and Yeo, J.D. 2016. Insoluble-bound phenolics in food. Molecules. 21(9): e1216. https://doi.org/10.3390/molecules21091216

Shao, Y., Hu, Z., Yu, Y., Mou, R., Zhu, Z., and Beta, T. 2018. Phenolic acids, anthocyanins, proanthocyanidins, antioxidant activity, minerals and their correlations in non-pigmented, red, and black rice. Food Chemistry. 239: 733-741. https://doi.org/10.1016/j.foodchem.2017.07.009 
Shimoda, H., Aitani, M., Tanaka, J., and Hitoe, S. 2015. Purple rice extract exhibits preventive activities on experimental diabetes models and human subjects. Rice Research. 3(2): 137. https://doi.org/10.4172/2375-4338. 1000137

Sibian, M.S., Saxena, D.C., and Riar, C.S. 2017. Effect of germination on chemical, functional and nutritional characteristics of wheat, brown rice and triticale: a comparative study. Journal of the Science of Food and Agriculture. 97(13): 4643-4651. https://doi.org/10.1002/jsfa.8336

Sivamaruthi, B.S, Kesika, P., and Chaiyasut, C. 2018. Anthocyanins in Thai rice varieties: distribution and pharmacological significance. International Food Research Journal. 25(5): 2024-2032.

Thao, N.T.T., and Niwat, C. 2017. Effect of germinated colored rice on bioactive compounds and quality of fresh germinated colored rice noodle. KMUTNB International Journal of Applied Science and Technology. 11: 27-37. https://doi.org/10.14416/j.ijast.2017.12.008

Ti, H., Guo, J., Zhang, R., Wei, Z., Liu, L., Bai, Y., and Zhang, M. 2015. Phenolic profiles and antioxidant activity in four tissue fractions of whole brown rice. RSC Advances. 5: 507-518. https://doi.org/10.1039/C5RA15963F

Ti, H., Zhang, R., Zhang, M., Li, Q., Wei, Z., Zhang, Y., Tung, X., Deng, Y., Liu, L., and Ma, Y. 2014. Dynamic changes in the free and bound phenolic compounds and antioxidant activity of brown rice at different germination stages. Food Chemistry. 161: 337-344. https://doi.org/10.1016/ j.foodchem.2014.04.024

Upanan, S., Yodkeeree, S., Thippraphan, P., Punfa, W., Wongpoomchai, R., and Limtrakul Dejkriengkraikul, P. 2019. The proanthocyanidin-rich fraction obtained from red rice germ and bran extract induces HepG2 hepatocellular carcinoma cell apoptosis. Molecules. 24(4): 813. https://doi.org/10.3390/ molecules 24040813

Wakabayashi, K., Soga, K., Hoson, T., Kotake, T., Yamazaki, T., Higashibata, A., Ishioka, N., Shimazu, T., Fukui, K., Osada, I., et al. 2015. Suppression of hydroxycinnamate network formation in cell walls of rice shoots grown under microgravity conditions in space. PLoS One. 10(9): e0137992. https://doi.org/10.1371/journal.pone.0137992

Wang. Y., Li, M., Xu, F., Chai, L., Bao, J., and Shen, S. 2016. Variation in polyphenols, tocols, $\gamma$-aminobutyric acid, and antioxidant properties in whole grain rice (Oryza sativa L.) as affected by different germination time. Cereal Chemistry. 93(3): 268-274. https://doi.org/10.1094/CCHEM08-15-0171-R

Yamuangmorn, S., Dell, B., Du, X., Ren, Y., and Prom-u-thai, C. 2019. Simultaneous quantification of anthocyanins and phenolic acids in pigmented rice (Oryza sativa) using UPLC-PDA/ESI-Q-TOF. 
International Journal of Agriculture \& Biology. 21(3): 590-596. https://doi. org/10.17957/IJAB/15.0933

Zhang, M.W., Zhang, R.F., Zhang, F.X., and Liu, R.H. 2010. Phenolic profiles and antioxidant activity of black rice bran of different commercially available varieties. Journal of Agricultural and Food Chemistry. 58(13): 7580-7587. https://doi.org/10.1021/jf1007665

Zhu, Y., Sun, H., He, S., Lou, Q., Yu, M., Tang, M., and Tu, L. 2018. Metabolism and prebiotics activity of anthocyanins from black rice (Oryza sativa L.) in vitro. PLoS One. 13(4): e0195754. https://doi.org/10.1371/journal.pone. 0195754 